Conclusions Recreational surfers reveal a considerable injury frequency per $1000 \mathrm{~h}$ of exposure, independent of gender, surfer position or side. The greater incidence of lower-limb and shoulder injuries must be underlined, as well as the fact that collision/direct contact represents more than 50\% of the injury mechanisms.

\section{DO PHYSICAL CONTACTS AND HEAD CONTACTS DIFFER IN FEMALE ICE HOCKEY AND RINGETTE? A VIDEO- ANALYSIS STUDY}

${ }^{1}$ Emily E Heming, 'Alexandra J Sobry, ${ }^{1}$ Alexis L Cairo, ${ }^{1}$ Rylen A Williamson, ${ }^{1}$ Ash T Kolstad, 1,2,3,4,5,6,7 Carolyn A Emery. 'Sport Injury Prevention Research Centre, Faculty of Kinesiology, University of Calgary, Calgary, Canada; ${ }^{2}$ Alberta Children's Hospital Research Institute, University of Calgary, Calgary, Canada; ${ }^{3} \mathrm{O}^{\prime}$ Brien Institute for Public Health, University of Calgary, Calgary, Canada; ${ }^{4}$ Hotchkiss Brain Institute, University of Calgary, Calgary, Canada; ${ }^{5}$ McCaig Institute for Bone and Joint Health, University of Calgary, Calgary, Canada; ${ }^{6}$ Community Health Sciences, Cumming School of Medicine, University of Calgary, Calgary, Canada; ' Department of Paediatrics, Cumming School of Medicine, University of Calgary, Calgary, Canada

\subsection{6/bjsports-2021-IOC.205}

Background A Canadian study reports the highest concussion rates in ringette and ice hockey, compared to other female team sports. Although high-intensity physical contacts (PC) are prohibited in both sports, player-to-player PCs accounted for $58-64 \%$ of injuries.

Objective To compare incidence rates (IR) of in-game PCs, head contacts (HC), and suspected injuries in female varsity ice hockey and ringette.

Design Cross-sectional.

Setting Canadian ice hockey arenas.

Participants Female university ringette and ice hockey tournament/playoff games in the 2018-2019/2019-2020 seasons.

Assessment of Risk Factors Game video-recordings were analyzed using Dartfish video-analysis software. Validated criteria were used to assess PC intensity (level 1-5), PC type (e.g., trunk contact, push), $\mathrm{HC}$ type (i.e., $\mathrm{HC} 1=$ direct player-toplayer, $\mathrm{HC} 2=$ indirect environmental), and suspected injury (i. e., concussion, musculoskeletal).

Main Outcome Measurements Univariate Poisson regression analyses (adjusted for cluster by team, offset by game-minutes) was used to estimate PC and HC IRs and incidence rate ratios (IRRs, 95\% confidence intervals) comparing sports.

Results Analyses of 36 team-games $(n=18$ ringette, $n=18$ ice hockey) revealed that ringette had a $19 \%$ lower rate of PCs $(\mathrm{IR}=310.38 \quad$ contacts $/ 100 \quad$ team-minutes, $95 \% \mathrm{CI} ; 285.40-$ $337.54)$ than ice hockey $(\mathrm{IR}=382.48$ contacts $/ 100$ teamminutes, 95\%CI;356.80-410.00) $\quad(\mathrm{IRR}=0.81, \quad 95 \% \mathrm{CI} ; 0.73-$ 0.90). Ringette had a $68 \%$ higher rate (IRR $=1.68,95 \%$ CI:1.22-2.31) of total HCs (IR=17.92 contacts $/ 100$ teamminutes, 95\%CI;14.71-21.83) compared to ice hockey $(\mathrm{IR}=10.67$ contacts $/ 100$ team-minutes, 95\%CI;8.28-13.75). Ringette had a 3 -fold higher rate $(\mathrm{IRR}=3.11$, 95\%CI;1.13$8.60)$ of suspected injury (IR $=1.46 \mathrm{HCs} / 100$ team-minutes, 95\%CI;0.72-2.93) compared to ice hockey (IR=0.47 HCs/100 team-minutes, 95\% CI;0.22-1.00).

Conclusions This study demonstrated a lower rate of PCs in ringette than female ice hockey. However, ringette had a significantly higher rate of HCs and suspected injuries than ice hockey. These findings can inform future research targeting prevention strategies in both sports.

\section{INJURY AND ILLNESS EPIDEMIOLOGY DURING THE 53RD FIS NORDIC WORLD SKI CHAMPIONSHIPS 2021 IN OBERSTDORF: A PROSPECTIVE COHORT STUDY}

${ }^{1}$ Karsten Hollander, ${ }^{2,6}$ Kastner Tom, ${ }^{3}$ Weith Moritz, ${ }^{4}$ Disch Alexander, ${ }^{5}$ Porzig Florian, 2,6 Wolfarth Bernd, ${ }^{7,8}$ Edouard Pascal, ${ }^{1,9}$ Junge Astrid. 'MSH Medical School Hamburg, Hamburg, Germany; ${ }^{2}$ Institute for Applied Training Science, Leipzig, Germany; ${ }^{3}$ University of Bonn, Bonn, Germany; 'University Medicine 'Carl Gustav Carus' at the TU Dresden, Dresden, Germany; ${ }^{5}$ Gemeinschaftspraxis Drs. med. Porzig and Köberle, Fischen, Germany; ${ }^{6}$ Charité - Universitätsmedizin Berlin and Humboldt-Universität zu Berlin, Berlin, Germany; ${ }^{7}$ University Jean Monnet, Saint Etienne, France; ${ }^{8}$ University Hospital of Saint-Etienne, SaintEtienne, France; ${ }^{9}$ Swiss Concussion Center, Schulthess Klinik, Zürich, Germany

\subsection{6/bjsports-2021-IOC.206}

Background Nordic skiing consist of cross-country skiing (CC), ski jumping (SJ) and Nordic combined (NC). Only little injury and illness data from elite competitions in these sports are currently available.

Objective To analyse injuries and illnesses during the FIS Nordic World Ski Championships 2021.

Design Prospective cohort study.

Setting FIS Nordic World Ski Championships in Oberstdorf, Germany, $23^{\text {rd }}$ February to $7^{\text {th }}$ March 2021.

Participants All registered athletes $(n=663)$.

Main Outcome Measure Daily report of newly incurred injuries and illnesses according to the respective IOC consensus statement (2020) by the medical teams.

Results About half of the nations (32/65), covering 51.6\% of the registered athletes $(n=342)$, participated in the study and returned $88.4 \%$ of the daily report forms. During the 12 championships days, 16 injuries were reported (incidence rate: $4.6 \%, 95 \% \mathrm{CI} 2.4$ to $6.9 \%$ ), 12 in $\mathrm{CC}$ and 2 injuries each in NC and SJ. Six injuries affected the upper and 6 the lower extremities, 2 the lumbar-sacral spine/buttock and 2 the head. Most injuries occurred suddenly $(n=13), 3$ gradually. Eleven injuries (69\%) were non-time-loss, Four injuries resulted in an estimated time-loss of 3-7 days, 1 in an estimated time-loss of 21 days (fracture of metacarpal bone).

Out of the 16 illnesses (incidence rate: 4.6\%, 95\%CI 2.4 to $6.9 \%$ ), 11 were reported in CC, 3 in NC and 2 in SJ.. Regarding etiology, 5 illnesses were environmental (4 exerciserelated and 1 non-exercise related), 4 infectious, 3 allergic, 2 metabolic/nutritional, 1 degenerative/chronic and 1 unknown. Most illness occurred suddenly $(n=10), 4$ gradually and 2 had a mixed mode of onset. Twelve illnesses (75\%) were nontime-loss. Three illnesses resulted in an estimated time-loss of 3 days, 1 in an estimated time-loss of 20 days (COVID-19 infection).

Conclusion The injuries or illnesses incidence rate was lower than in Winter Olympic Games. The low illness rate might be due to COVID-19 hygiene measures.

\section{$224 \quad$ ABSTRACT WITHDRAWN}

